\title{
A Compact, Wideband, Dual Polarized CPW-Fed Asymmetric Slot Antenna for Wireless Systems
}

\author{
Shilpee Patil ${ }^{1}$ (D), Anil Kumar Pandey ${ }^{2}$ (D), Vijay Kumar Pandey ${ }^{2}$ (i) \\ ${ }^{I}$ Department of Electronics \& Communication Engineering, Noida Institute of Engineering \& Technology, \\ Greater Noida, India.Email: shilpeepatil21@gmail.com \\ ${ }^{2}$ Department of Electronics \& Communication Engineering, G.N.I.T., Greater Noida, India. Email: \\ anilpandey85@gmail.com \\ ${ }^{3}$ Department of Electronics \& Communication Engineering, Noida Institute of Engineering \& Technology, \\ Greater Noida, India.Email: vijaygpandey@yahoo.com
}

\begin{abstract}
Wideband, dual sense circularly polarized (CP), asymmetric circular slot fed by coplanar waveguide is proposed and designed. Dual polarizations are obtained by using a horizontal stub to the feed line and embedding the L-shaped strip onto the slotted ground plane. The simulated result of impedance bandwidth shows wideband performance is produced by four resonant modes. Some key parameters are studied to analyze the characteristics of the proposed antenna. The overall volume of the proposed antenna is $18 \mathrm{~mm} \times 18 \mathrm{~mm} \times 1.6 \mathrm{~mm}$. The measured value of $10 \mathrm{~dB}$ impedance bandwidth is $112 \%$ at frequencies from $4.2 \mathrm{GHz}$ to 14.9 GHz with voltage standing wave ratio $(V S W R) \leq 2$. The 3-dB axial ratio bandwidths are $39.3 \%$ for the lower band which senses righthand circular polarization (RHCP) and $2.8 \%$ for the upper band which senses left-hand circular polarization (LHCP) relative to the center frequency of $6.1 \mathrm{GHz}$ and $14.1 \mathrm{GHz}$, respectively. The proposed structure gives a good radiation pattern with moderate gain.
\end{abstract}

Index Terms - asymmetric slot antenna, circular polarization, CPW feed, wideband antenna.

\section{INTRODUCTION}

The microstrip patch antenna is a new kind of radiator, which is compatible with integrated circuit technology and offers advantages such as thin profile, light weight, low price, and conformability to a shaped surface. It is usually designed for single-mode linearly polarized (LP) operation that radiates only horizontally or vertically polarized waves [1]. To overcome this limitation, a multi-band CP antenna is needed. It is used to make independent data transmission and reception from the orientation of the transmitter and receiver and remove the multipath shortcomings. For CP radiation, a patch should support two orthogonal modes of the same amplitude however, $90^{\circ}$ phase difference. To achieve these modes a single patch with appropriate excitations or a properly structured array of patches with proper phasing is required. Using a printed slot antenna with coplanar waveguide (CPW) feed is one of the methods to prevent the increasing size of the antenna and improve the operating bandwidth. The main features of CPW feed are wider bandwidth, a single metallic layer, easily 
integrated with active elements, and a small mutual coupling between two adjacent lines of the coplanar structure.

In recent times, some techniques are utilized to produce circularly polarized antennas. Reference [2] proposed and investigated the stage 1 and stage 2 of a Koch fractal boundary CP microstrip antenna. In [3] and [4], a dual-band, dual sense CP antenna is obtained by four unequal linear slots incorporated to the annular slot and by two spiral-shaped slotted ground planes, respectively. A tripleband circularly polarized operation is achieved by a single layer, a single-feed antenna with asymmetrical fractal boundary is presented in [5]. A circular patch slotted with eight curves and a coaxial probe with the integrated disk also generates a dual sense polarization operation that is proposed in [6]. Another structure is proposed in [7] for dual sense polarization operation that consists of a bent feeding configuration with a slotted ground structure. To obtain dual-band circular polarization in [8], a rectangular and L-shaped adjusting stub is used additionally. The proposed design in [9] consists of the stacking of two truncated patches having an inclined slot and horizontal slits to produce quad-band circular polarization operation. Dual-band circularly polarized spiral slotloaded antenna is proposed in [10]. To achieve circular polarization incorporation of three slit arms of $\mathrm{L}$ shaped onto the hexagonal slot is presented in [11]. Various other slot combinations are reported to obtain broadband and multiband circular polarization with wide impedance bandwidth [12]-[20].

In view of the above kinds of literature, a novel structure of a CPW fed slot antenna consist of a horizontal stub and L-shaped strip to achieve RHCP and LHCP with the wideband operation is investigated. The designed small size dual CP antenna with size $18 \mathrm{~mm} \times 18 \mathrm{~mm} \times 1.6 \mathrm{~mm}$ operates over the impedance bandwidth of $10.7 \mathrm{GHz}(4.2-14.9 \mathrm{GHz})$ with the center frequency of $9550 \mathrm{MHz}$. The 3-dB axial ratio bandwidth (ARBW) for the lower band can reach as large as $2400 \mathrm{MHz}$ (4.9-7.3 $\mathrm{GHz}$ ) with the center frequency of $6100 \mathrm{MHz}$ and 3-dB ARBW for the upper band is $400 \mathrm{MHz}$ (13.914.3 GHz) with the center frequency of $4100 \mathrm{MHz}$.

\section{CONFIGURATION OF THE PROPOSED ANTENNA}

The proposed CPW-fed antenna is designed on the FR-4 substrate of dielectric constant ' $\varepsilon_{\mathrm{r}}$ ' $=4.4$ and a thickness of $1.6 \mathrm{~mm}$. Fig. 1 shows the simple and basic structure of the proposed antenna of the overall area $18 \mathrm{~mm} \times 18 \mathrm{~mm}$. It consists of an asymmetric circular slot of radius ' $R$ ' is etched onto the ground plane with L shaped strip on the right side of the corner. A horizontal stub of dimension $\left(\mathrm{L}_{\mathrm{s}} \times \mathrm{W}_{\mathrm{s}}\right)$ is added to the feed line, which plays a very important role in the antenna performance. Final optimized values for all parameters of the proposed antenna are listed in Table I. 


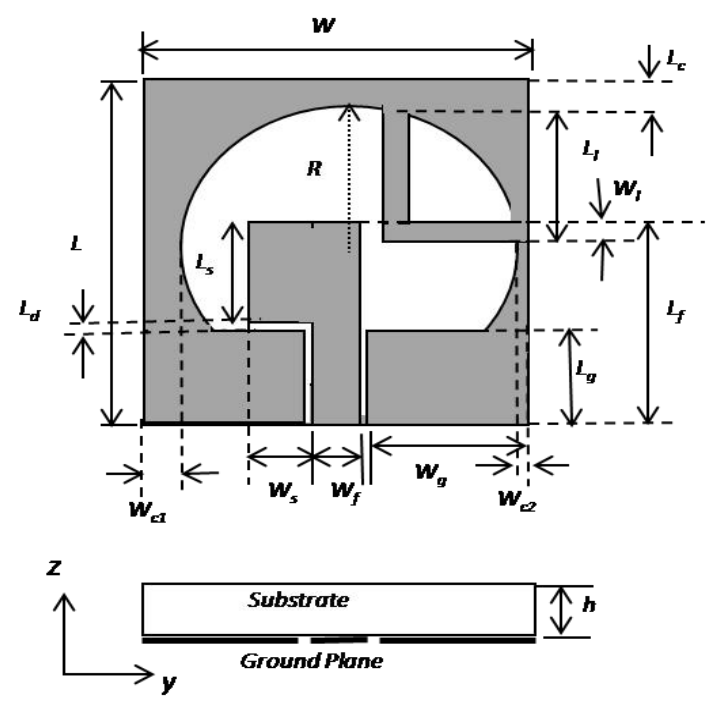

Fig. 1. Schematic diagram of the proposed antenna.

TABLE I. OPTIMIZED PARAMETERS OF THE PROPOSED ANTENNA

\begin{tabular}{|l|l|l|l|l|l|l|l|l|}
\hline Parameters & $W$ & $W_{f}$ & $W_{s}$ & $W_{g}$ & $W_{l}$ & $W_{c 1}$ & $W_{c 2}$ & $H$ \\
\hline Value(mm) & 18 & 2 & 3 & 7.7 & 1 & 1.5 & 0.5 & 1.6 \\
\hline Parameters & $L$ & $L_{f}$ & $L_{s}$ & $L_{g}$ & $L_{l}$ & $L_{c}$ & $L_{d}$ & $R$ \\
\hline Value(mm) & 18 & 11 & 5.5 & 5 & 7 & 1 & 0.5 & 8 \\
\hline
\end{tabular}

The asymmetric structure of the antenna design generates two different modes of the radiated fields. Therefore, by setting the perturbation segment to the edge of the circular slot, the generated mode is separated into two orthogonal modes Ex and Ey. The radiated fields excited by these two modes are in general perpendicular to each other and orthogonally polarized in the direction of maximum radiation. This enables the antenna to operate as a $\mathrm{CP}$ radiator. This proposed antenna has a number of advantages such as small size, wide impedance bandwidth and can excite dual sense CP radiation without using an external polarizer as compared to other dual sense CP radiators.

\section{EVOLUTION OF THE PROPOSED ANTENNA}

To obtain large impedance bandwidth and dual sense CP operation, two main structures have been embedded in the proposed antenna: one is the horizontal stub on the feed line and the other is an Lshaped strip onto the right side of the top of the circularly slotted ground plane. The dimensions of the horizontal stub on the feed line are optimized for good impedance matching. Throughout various simulations, appropriate dimensions are obtained. To examine the effect of modified structures on antenna performance, four antennas with or without the modified structures are defined and illustrated in Fig. 2 Therefore, optimized simulated results of S11 and axial ratio for all three prototypes and proposed antenna are shown in Figs. 3(a) and 3(b). It is observed that the combination of two 
structures, the stub on the feed and the L shaped strip improves the impedance and ARBW effectively.

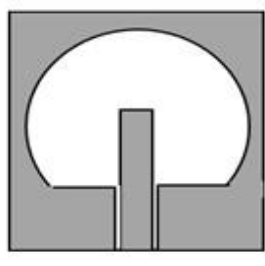

Antenna I

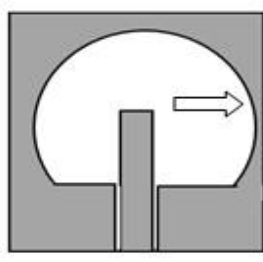

Antenna II

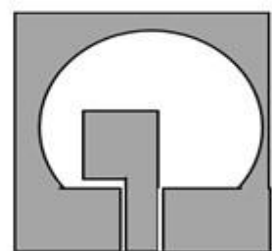

Antenna III

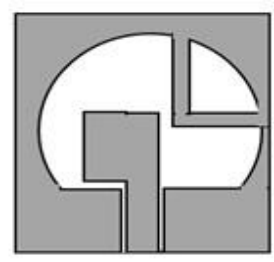

Proposed Antenna

Fig. 2. Antenna prototypes.

Impedance bandwidth results for antenna I and antenna II give only shifted lower and upper resonance frequency. Second and third resonance frequency does not appear below -10 dB for the S11 value. In this case, results for axial ratio are not appreciable. Antenna III gives a good and wideband S11 with four resonance frequencies but the axial ratio is not below 3-dB. Finally, the antenna with an L-shaped strip lying onto the top right side of the circularly slotted ground plane for generating two orthogonal resonant modes is designed. Analysis of the designed antenna gives the simulated results of impedance bandwidth from $4.2 \mathrm{GHz}$ to $14.9 \mathrm{GHz}$ of $112 \%$ relative to the center frequency of 9.55 GHz. Therefore, $3-\mathrm{dB}$ ARBW for the lower band is $39.3 \%$ and for the upper band is $2.8 \%$ relative to the center frequency of $6.1 \mathrm{GHz}$ and $14.1 \mathrm{GHz}$, respectively.

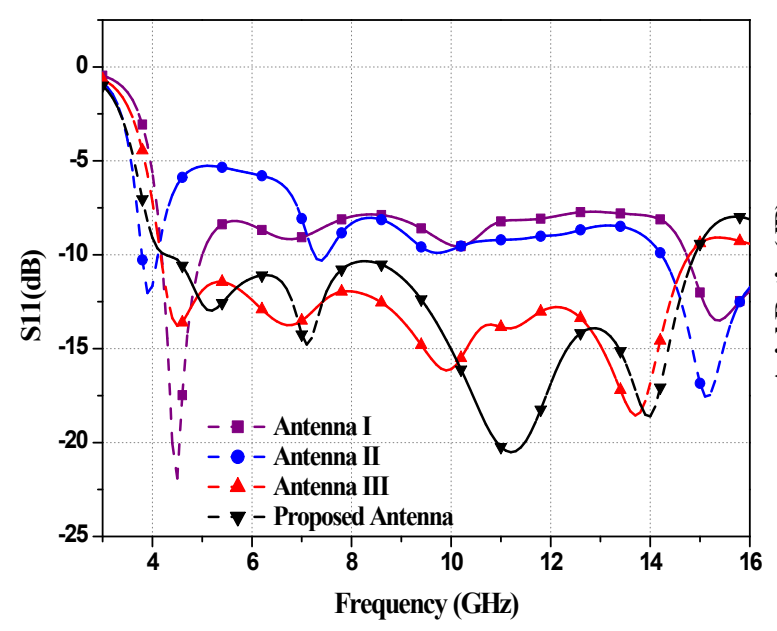

(a)

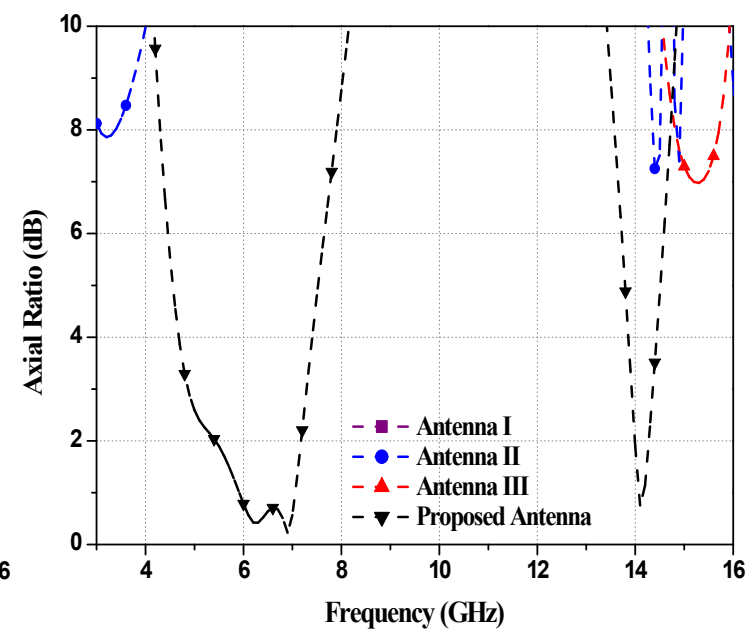

(b)

Fig. 3. Simulated results for Antenna I, Antenna II, Antenna III, and Proposed Antenna of (a) S11, and (b) axial ratio.

\section{PARAMETRIC ANALYSIS}

Simulated results are analyzed by using Ansoft High-Frequency Structure Simulator (HFSS-V13) software, which is commercially available. HFSS is the electromagnetic solver used for numerical investigation and optimization of the proposed antenna. To obtain a good result, different parameters of the antenna structure are varied and optimized values are considered. 
This section elaborates the performance-process of the proposed antenna through parametric simulation. A study on the parametric process has been made in order to get optimized values for certain antenna dimensions such as stub width on the feed and L-shaped strip width on the slotted ground. In this process, the optimized value of the parameter is obtained by varying the value of that parameter and keeps all parameters constant at the time of the simulation.

\section{A. Varying stub width ' $W_{s}$ ' (Without L-shaped strip)}

The variation in the value of stub width, without L-shaped strip, is used to enhance the S11 characteristic. The $\mathrm{S} 11$ characteristics and ARBW for the stub width ' $\mathrm{W}_{\mathrm{s}}$ ' from $2 \mathrm{~mm}$ to $3.5 \mathrm{~mm}$ are shown in Figs. 4(a) and 4(b). The analysis shows that the impedance bandwidth increases as the stub width $\mathrm{W}_{\mathrm{s}}$ are increased from $2.5 \mathrm{~mm}$ to $3 \mathrm{~mm}$. Further increase in $\mathrm{W}_{\mathrm{s}}$, decreases impedance bandwidth and shows an insignificant change in ARBW. From the result, $\mathrm{W}_{\mathrm{s}}=3 \mathrm{~mm}$ shows wide impedance bandwidth but linearly polarized characteristics of the proposed antenna.

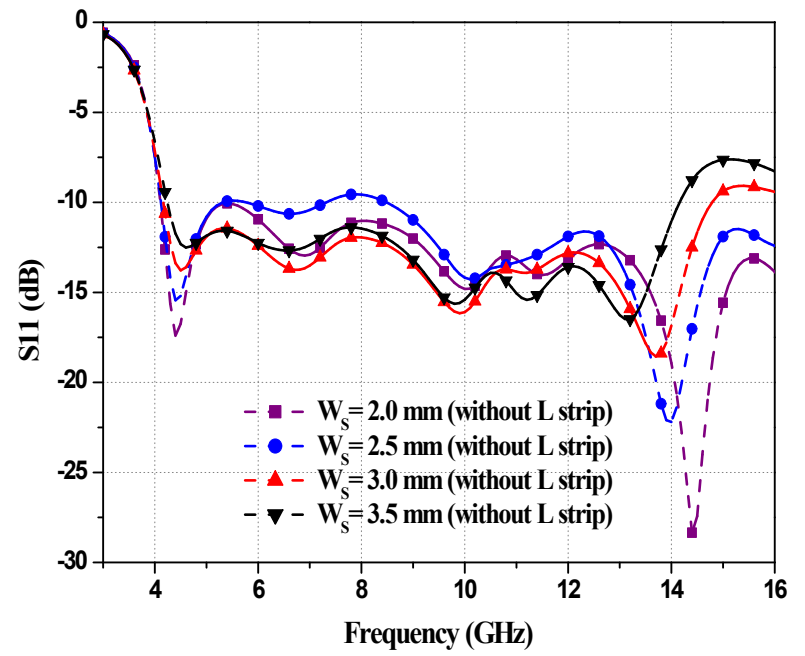

(a)

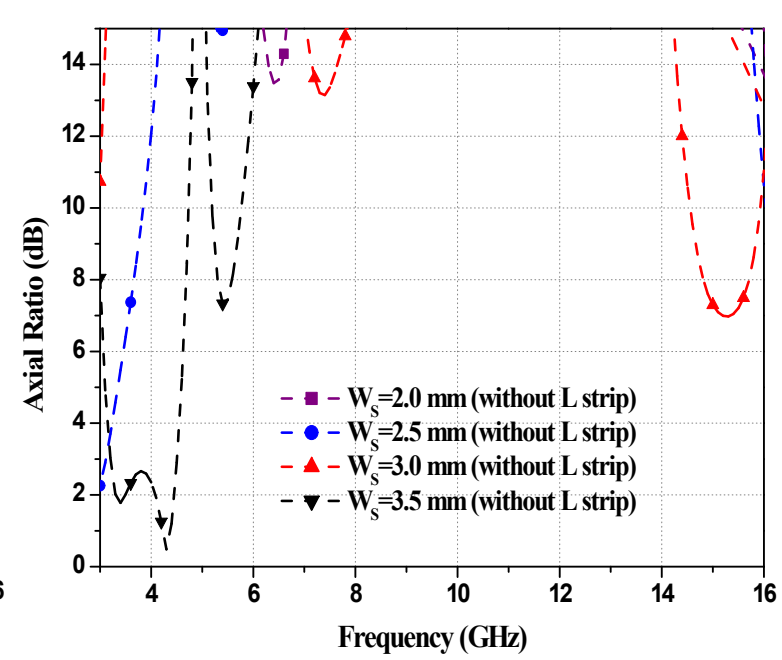

(b)

Fig. 4. Simulated results for variations in the stub width $\mathrm{W}_{\mathrm{s}}$ (without L-shaped strip); (a) S11, and (b) axial ratio.

\section{B. Varying L-shaped strip width ' $W_{l}$ '}

The optimization of thickness of the L-shaped strip can be used for the best circularly polarized performance to the antenna. The effect of different values of $\mathrm{W}_{1}$ on S11 characteristics of the proposed antenna illustrated in Fig. 5 (a).

The impedance bandwidth decreases with an increase in the width of the L-shaped strip. At $\mathrm{W}_{1}=1$ mm S11 covers a wide range of frequencies. The ARBW characteristic for different values of $\mathrm{W}_{1}$ is illustrated in Fig. 5 (b). The width of the L-shaped strip changes from $0.5 \mathrm{~mm}$ to $2 \mathrm{~mm}$. The proposed antenna achieves ARBW at upper resonance band at $\mathrm{W}_{1}=0.5 \mathrm{~mm}$. When $\mathrm{W}_{1}=1 \mathrm{~mm}$, the antenna achieves dual circular polarization bandwidth, in which lower ARBW consists of both lower resonance frequency of $5.2 \mathrm{GHz}$ and $7.1 \mathrm{GHz}$. After that increasing the width of the L-shaped strip lower ARBW decreases and impedance bandwidth also decreases rapidly. Therefore, a wide 
impedance band and better ARBW are achieved at $\mathrm{W}_{\mathrm{l}}=1 \mathrm{~mm}$. Hence, $\mathrm{W}_{\mathrm{s}}=3 \mathrm{~mm}$ and $\mathrm{W}_{\mathrm{l}}=1 \mathrm{~mm}$ are considered as optimized values for the proposed antenna. Additionally, to achieve better performance of the antenna a thorough parametric analysis is followed out.

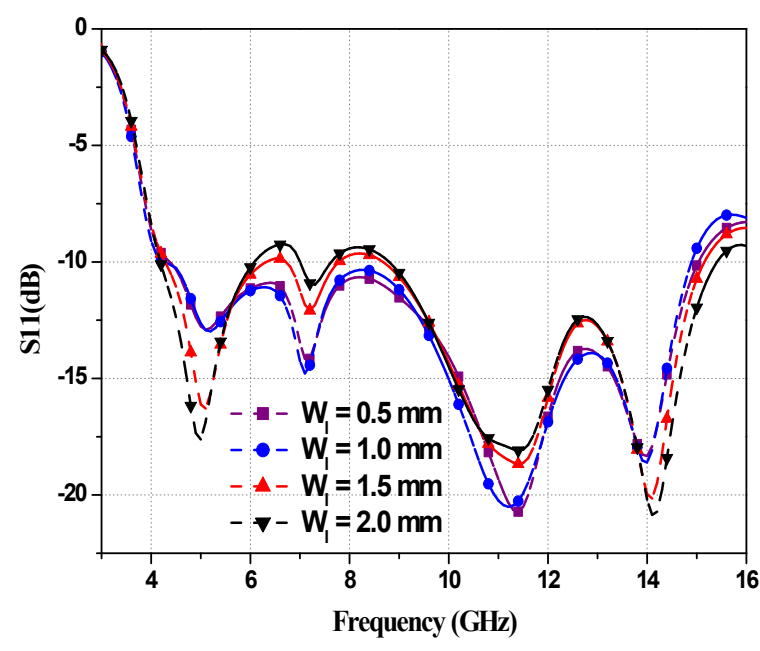

(a)

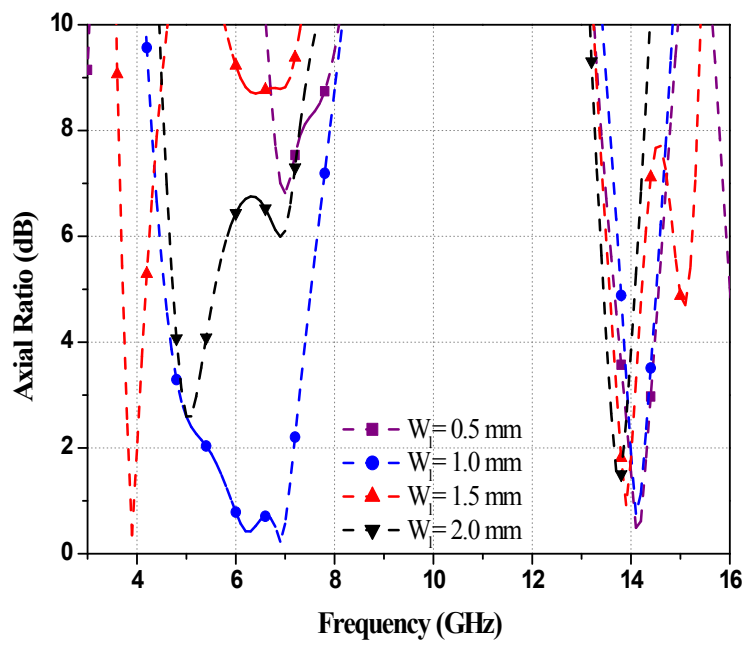

(b)

Fig. 5. Simulated results for variations in the $\mathrm{L}$ shaped strip width $\mathrm{W}_{1}$; (a) S11, and (b) axial ratio.

\section{ANALYSIS OF THE CURRENT DISTRIBUTION}

To realize the operation of the generation of the circularly polarized wave for the proposed antenna, the vector surface current distribution on the feed and slotted ground for different time phases is examined in this section. Figs. 6(a) and 6(b) illustrates the distribution of surface current onto the surface of the proposed antenna for the time phases at $\omega \mathrm{t}=0^{\circ}, \omega \mathrm{t}=90^{\circ}, \omega \mathrm{t}=180^{\circ}$ and $\omega \mathrm{t}=270^{\circ}$. These analyses are operated at $5.2 \mathrm{GHz}$ and $7.1 \mathrm{GHz}$, separately. At $5.2 \mathrm{GHz}$, leading current vectors for time phase $0^{\circ}$ and $90^{\circ}$ are in $-\mathrm{x}$ and $+\mathrm{y}$ direction. On the other hand, the current vectors for time phase $180^{\circ}$ and $270^{\circ}$ are the same in amplitude but opposite in phase of $0^{\circ}$ and $90^{\circ}$, respectively. However, the surface current vector rotated in a clockwise direction in the xy plane, which shows right-hand circularly polarized wave is generated in the upper-half space of the radiation space. Fig. 6(b) illustrates the surface current vector at $7.1 \mathrm{GHz}$ is rotated in a clockwise direction in the xy plane, which again shows right-hand circularly polarized wave is generated in the upper-half space of the radiation. Finally, Fig. 7 illustrates the surface current distribution on the slotted ground of proposed antenna at $14.1 \mathrm{GHz}$ for the time phases of $\omega \mathrm{t}=0^{\circ}$, $\omega \mathrm{t}=90^{\circ}, \omega \mathrm{t}=180^{\circ}$ and $\omega \mathrm{t}=270^{\circ}$. The leading surface current vectors in the time phase of $180^{\circ}$ and $270^{\circ}$ are the same in amplitude but opposite in phase of $0^{\circ}$ and $90^{\circ}$, respectively. As a result, the surface current vector rotates in an anticlockwise direction in the xy plane. Therefore, antenna radiated as left-hand circularly polarized in the upperhalf space at $14.1 \mathrm{GHz}$ of the frequency.I 


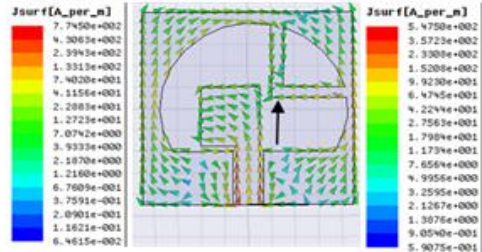

(i) $\omega \mathrm{t}=0^{\circ}$

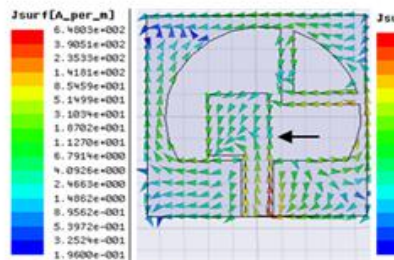

(i) $\omega t=0^{\circ}$

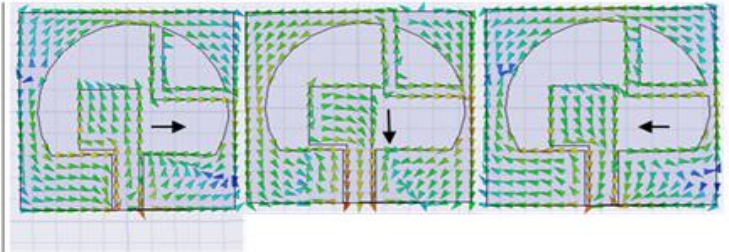

(ii) $\omega \mathrm{t}=90^{\circ}$

(iii) $\omega \mathrm{t}=180^{\circ}$

(iv) $\omega t=270^{\circ}$

(a)
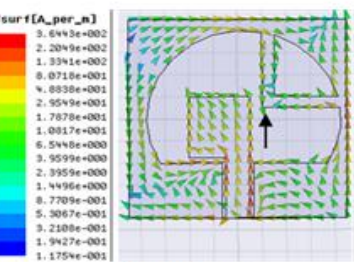

(ii) $\omega \mathrm{t}=90^{\circ}$

(b)

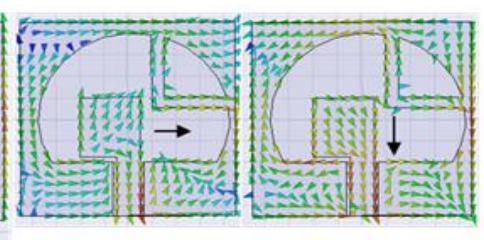

(iii) $\omega \mathrm{t}=180^{\circ}$

(iv) $\omega \mathrm{t}=270^{\circ}$

Fig.6. Simulated surface current distributions on the surface of proposed antenna at (a) $5.2 \mathrm{GHz}$, and (b) $7.1 \mathrm{GHz}$.

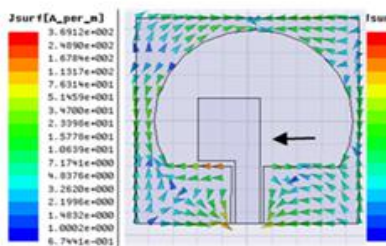

(i) $\omega \mathrm{t}=0^{\circ}$

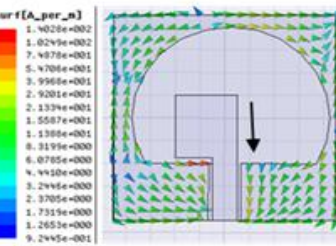

(ii) $\omega \mathrm{t}=90^{\circ}$

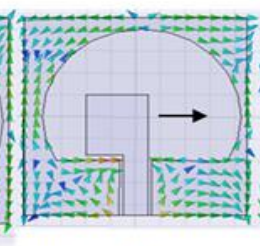

(iii) $\omega \mathrm{t}=180^{\circ}$

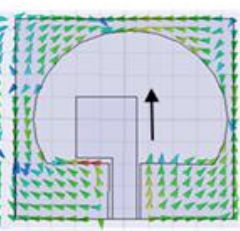

(iv) $\omega t=270^{\circ}$

Fig. 7. Simulated surface current distributions on the ground plane of the proposed antenna at $14.1 \mathrm{GHz}$.

\section{RESULTS AND DISCUSSION}

Experimental results are obtained by using an Agilent ${ }^{\mathrm{TM}}$ PNA-L series vector network analyzer. Fig. 8 shows the image of a fabricated circularly polarized antenna fed by an SMA connector of $50-\Omega$ along the coplanar waveguide feed line.

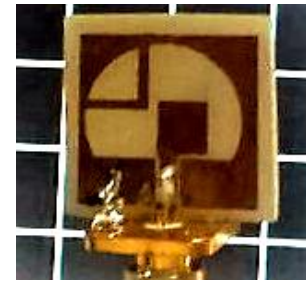

Fig.8. Fabricated prototype of the proposed antenna.

\section{A. S11 and axial ratio bandwidth}

In this section, simulated and measured results for S11 and axial ratio are compared and explained for the proposed antenna. The designed antenna operates over the impedance bandwidth of $10.7 \mathrm{GHz}$ at frequencies from $4.2 \mathrm{GHz}$ to $14.9 \mathrm{GHz}$. The 3-dB ARBW for the lower band can reach as large as $2400 \mathrm{MHz}$ from $4.9 \mathrm{GHz}$ to $7.3 \mathrm{GHz}$ and for the upper band it is $400 \mathrm{MHz}$ from $13.9 \mathrm{GHz}$ to 14.3 GHz. Figs. 9(a) and 9(b) illustrates the graph of S11 and axial ratio, respectively. A little difference is 
observed between simulated and measured results, which come from fabrication tolerance and soldering of the SMA connector. Table II listed the details of some important properties of the proposed antenna at a totally different resonance frequency within the operating band. It shows, the proposed antenna becomes an excellent choice for wideband applications, where a compact $\mathrm{CP}$ antenna is preferred.

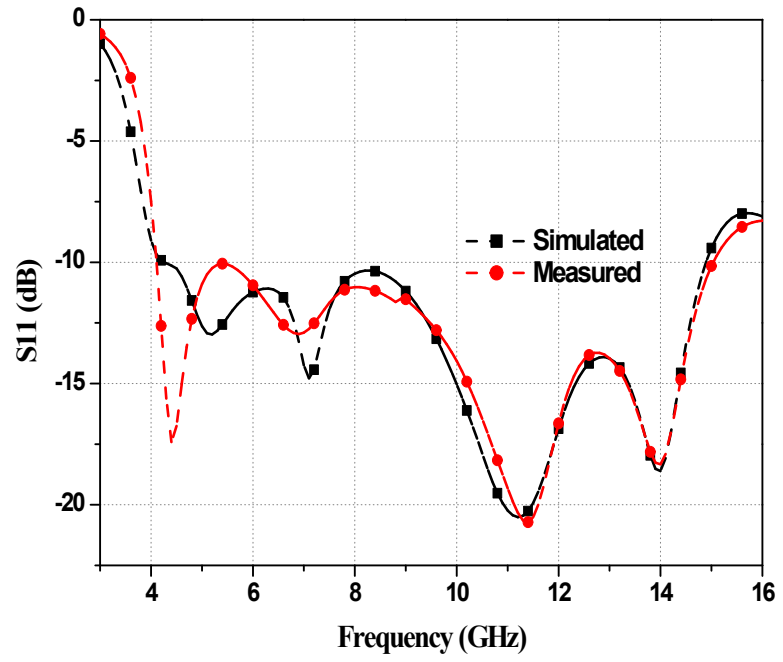

(a)

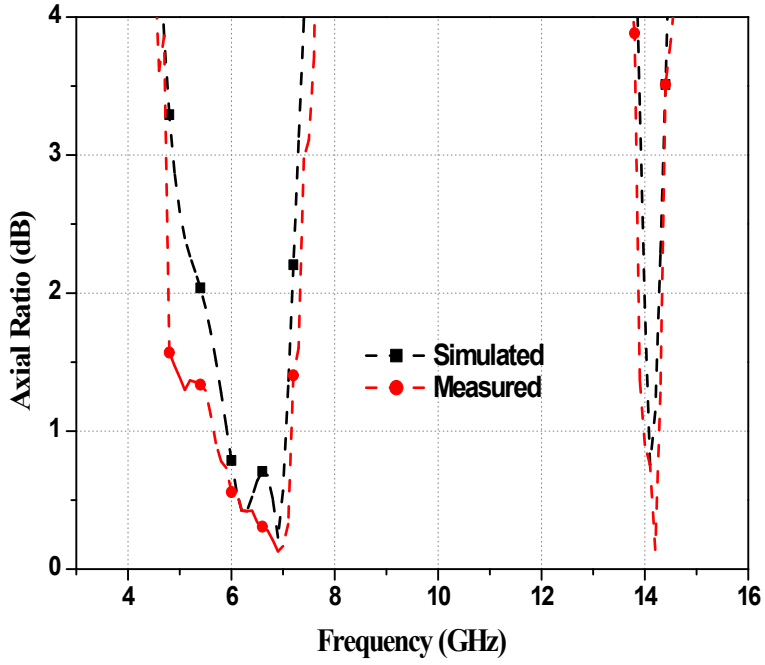

(b)

Fig. 9. Experimental of results of proposed antenna; (a) S11, and (b) axial ratio.

TABLE II. PROPERTIES OF PROPOSED ANTENNA AT THE DIFFERENT RESONANCE FREQUENCY

\begin{tabular}{ccccc}
\hline $\begin{array}{c}\text { Antenna } \\
\text { Properties }\end{array}$ & Value 1 & Value 2 & Value 3 & Value 4 \\
\hline Frequency(GHz) & 5.2 & 7.1 & 11.2 & 14.1 \\
Polarization & RHCP & RHCP & LP & LHCP \\
Gain(dBic) & 3.7 & 1.6 & 4.2 & 1.8 \\
VSWR & 1.6 & 1.4 & 1.2 & 1.3 \\
& Wireless LAN IEEE & Military & Fixed satellite & Fixed satellite \\
Applications & 802.11 a, Satellite & satellite & service(downlink) & service(uplink) \\
& Communication(uplink) & communication & & \\
\hline
\end{tabular}

\section{B. Gain and VSWR}

In this section, the simulated and measured results, including the gain and VSWR of the proposed antenna are explained to verify its performance. The measured and simulated results of gain versus frequency are illustrated in Fig. 10(a). It shows the gain of the designed antenna at four different resonance frequencies are $3.7 \mathrm{dBic}, 1.6 \mathrm{dBic}, 4.2 \mathrm{dBic}$ and $1.8 \mathrm{dBic}$, respectively. The simulated and measured results of VSWR of the proposed antenna are inappropriate settlement with each other, as shown in Fig. 10(b). The results indicate that the design has VSWR $<2$ throughout the operating band $(4.2-14.9 \mathrm{GHz})$. 


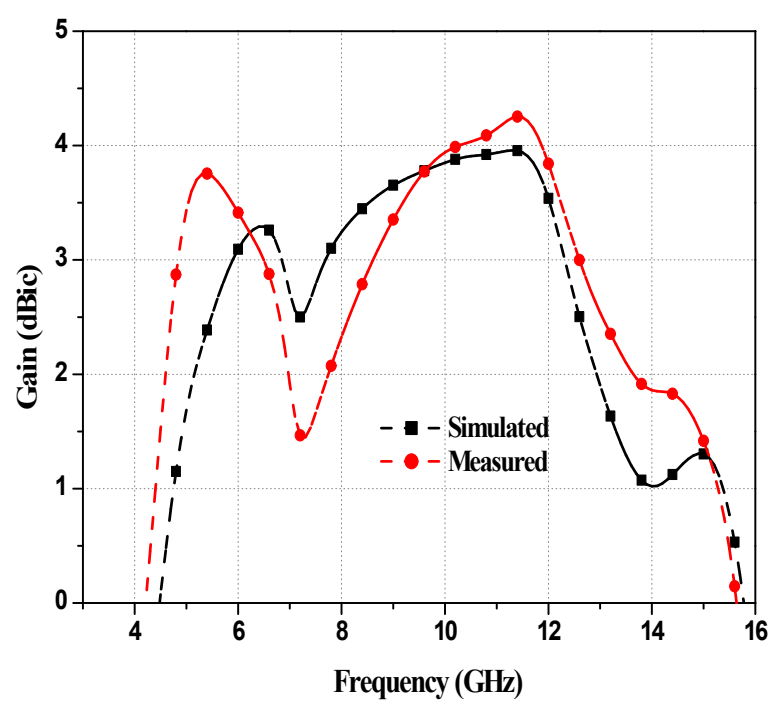

(a)

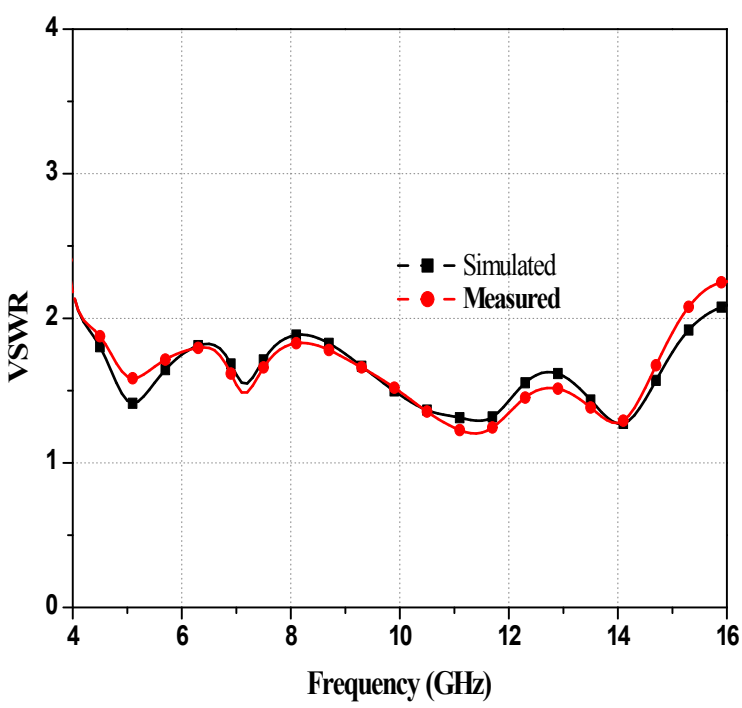

(b)

Fig. 10. Experimental results for the proposed antenna; (a) Gain, and (b) VSWR.

\section{Radiation patterns}

In this section, simulated and measured normalized radiation patterns of the proposed antenna at completely different resonant frequencies are plotted. Fig. 11 shows that the radiation patterns of the proposed antenna at $\varphi=0^{\circ}$ and $\varphi=90^{\circ}$ are plotted at $5.2 \mathrm{GHz}, 7.1 \mathrm{GHz}, 11.2 \mathrm{GHz}$, and $14.1 \mathrm{GHz}$. The measured and simulated radiation patterns are matched nicely with each other. It is observed from patterns that the antenna is radiated RHCP wave at $5.2 \mathrm{GHz}$ and $7.1 \mathrm{GHz}$, whereas LHCP wave at 14.1 GHz in $+\mathrm{z}$ direction. At the same time, the proposed antenna shows linear polarization at 11.2 $\mathrm{GHz}$.

Table III summarized the radiation properties of the designed antenna. The 3-dB half-power beamwidth for the xz plane and the yz plane at different resonance frequencies are listed in this table.

Table IV shows a brief comparison between the proposed antenna and the antenna presented in [3][11]. It is observed that the proposed antenna consists of a low profile, small size, wide impedance bandwidth with dual sense circularly polarized radiation for dual-band, and a good ARBW for both bands. This shows that the proposed antenna is better than other listed antennas in Table IV. 

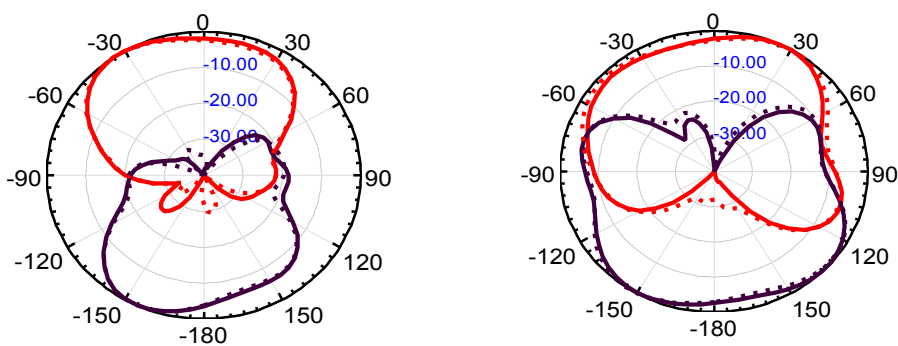

(a) $5.2 \mathrm{GHz}$
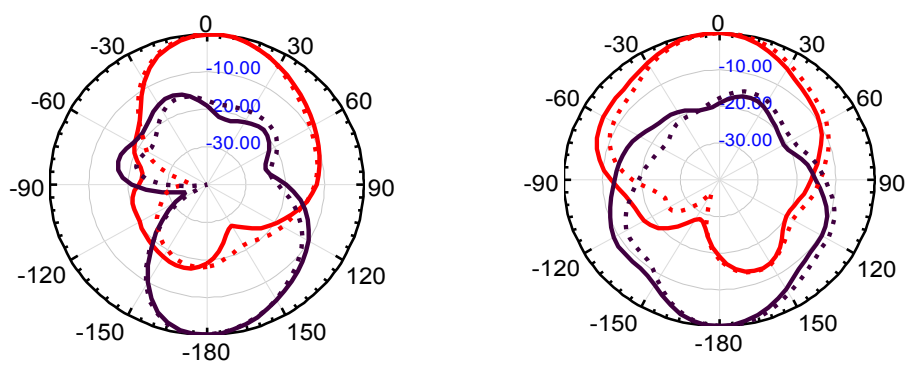

(b) $7.1 \mathrm{GHz}$
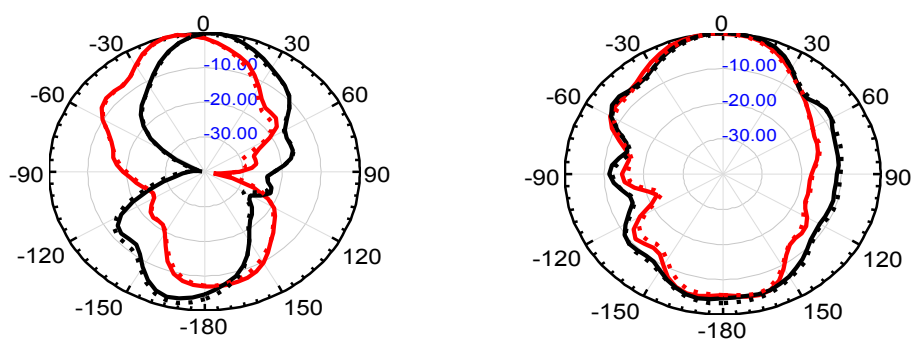

(c) $11.2 \mathrm{GHz}$
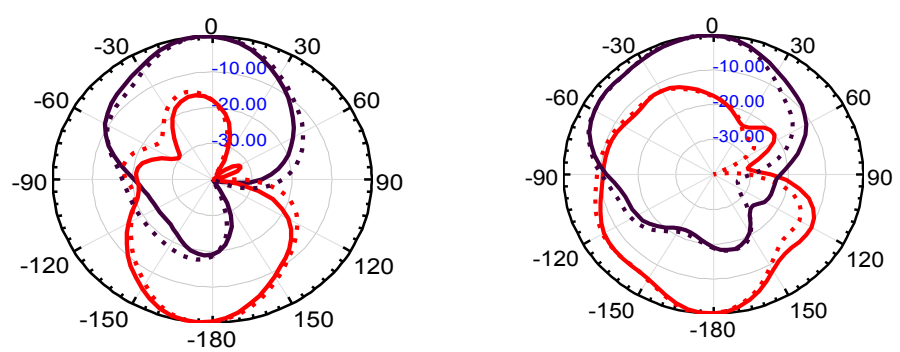

(d) $14.1 \mathrm{GHz}$

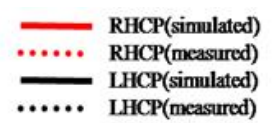

Fig.11. Experimental results for the radiation pattern of proposed antenna at $\varphi=0^{\circ}$ and $\varphi=90^{\circ}$. 
TABLE III. SIMULATED AND MEASURED RADIATION PATTERN CHARACTERISTICS

\begin{tabular}{|c|c|c|c|c|}
\hline \multirow[t]{2}{*}{$\begin{array}{c}\text { Frequency } \\
\text { (GHz) }\end{array}$} & \multicolumn{2}{|c|}{$\begin{array}{c}\text { Simulated HPBW } \\
\text { (Degree) }\end{array}$} & \multicolumn{2}{|c|}{$\begin{array}{c}\text { Measured HPBW } \\
\text { (Degree) }\end{array}$} \\
\hline & $\varphi=0^{\circ}$ & $\varphi=90^{\circ}$ & $\varphi=0^{\circ}$ & $\varphi=90^{\circ}$ \\
\hline $5.2 \mathrm{GHz}$ & 83 & 60 & 85 & 62 \\
\hline $7.1 \mathrm{GHz}$ & 49 & 57 & 50 & 60 \\
\hline 1 & 37 & 48 & 41 & 47 \\
\hline \multicolumn{5}{|l|}{$.2 \mathrm{GHz}$} \\
\hline $14.1 \mathrm{GHz}$ & 40 & 92 & 43 & 91 \\
\hline
\end{tabular}

TABLE IV. COMPARISON BETWEEN DIFFERENT TYPES OF CP ANTENNAS

\begin{tabular}{|c|c|c|c|c|c|c|}
\hline Ref. & $\begin{array}{l}\text { Antenna } \\
\text { Category }\end{array}$ & $\begin{array}{c}\text { Antenna } \\
\text { area } \\
\left(\mathbf{m m}^{2}\right)\end{array}$ & Feed Method & $\begin{array}{c}\text { Impedance } \\
\operatorname{BW}(\%)\end{array}$ & ARBW(\%) & $\begin{array}{c}\text { Polarization } \\
\text { Type }\end{array}$ \\
\hline$[3]$ & Ring Slot & $80 \times 80$ & $\begin{array}{l}\text { Microstrip Line } \\
\text { Feeding }\end{array}$ & $26.7 \%, 11.3 \%$ & $6.1 \%, 6.0 \%$ & RHCP,LHCP \\
\hline [4] & Ring Slot & $70 \times 70$ & CPW Feeding & $8.7 \%, 23 \%$ & $8.4 \%, 19.24 \%$ & LHCP,RHCP \\
\hline [5] & Fractal Slot & $50 \times 50$ & $\begin{array}{c}\text { Coaxial Probe } \\
\text { Feeding }\end{array}$ & $8.7 \%, 2.4 \%, 5 \%$ & $\begin{array}{c}3.2 \%, 1.6 \% \\
3.0 \%\end{array}$ & RHCP \\
\hline [6] & Curved Slot & $60 \times 60$ & $\begin{array}{l}\text { Coaxial Probe } \\
\text { Feeding }\end{array}$ & $0.48 \%, 0.73 \%$ & $10.7 \%, 9.6 \%$ & LHCP,RHCP \\
\hline [7] & Open Slot & $50 \times 60$ & Bent Feeding & $92.2 \%$ & $4.15 \%, 4.55 \%$ & RHCP,LHCP \\
\hline [8] & Complementary & $42 \times 30$ & $\begin{array}{l}\text { Microstrip Line } \\
\text { Feeding }\end{array}$ & $0.16 \%, 34.4 \%$ & $1.6 \%, 11.89 \%$ & RHCP,LHCP \\
\hline [9] & Stacked patch & $\approx 25 \times 25$ & $\begin{array}{l}\text { Coplanar } \\
\text { capacitive- } \\
\text { feeding }\end{array}$ & $55.46 \%$ & $\begin{array}{c}0.98 \%, 4.275 \\
\%, 0.8869 \%, 1 . \\
35 \%\end{array}$ & LHCP \\
\hline$[10]$ & Spiral Slot & $100 \times 100$ & $\begin{array}{l}\text { Microstrip Line } \\
\text { Feeding }\end{array}$ & $18.2 \%, 18.4 \%$ & $4.5 \%, 3.5 \%$ & RHCP,LHCP \\
\hline [11] & Hexagonal Slot & $60 \times 60$ & $\begin{array}{c}\text { Tapered } \\
\text { Microstrip } \\
\text { feeding }\end{array}$ & $33.16 \%, 22.72 \%$ & $\begin{array}{c}1.7 \%, 3.86 \%, 5 \\
.23 \%\end{array}$ & RHCP \\
\hline Proposed & Circular Slot & $18 \times 18$ & CPW Feeding & $112 \%$ & $39.3 \%, 2.8 \%$ & RHCP,LHCP \\
\hline
\end{tabular}

\section{CONCLUSION}

This paper proposed a CPW-fed, wideband, dually polarized asymmetric slot antenna. The proposed antenna senses all three polarizations linear, right-hand, and left-hand $\mathrm{CP}$ at different resonant frequencies. The addition of a horizontal strip with CPW feed is used to improve the overall impedance bandwidth and an L-shaped strip on the slotted ground is placed to achieve circularly polarized radiation. A good radiation pattern and enough gain across the operating band are achieved Brazilian Microwave and Optoelectronics Society-SBMO received 0 April 2020; for review 0 April 2020; accepted 0 Month 2019 
from the proposed antenna. The small deviation between experimental results comes out from the environmental effect by measurement and manufacturing tolerances. The experimental results show that the $-10 \mathrm{~dB}$ impedance bandwidths obtained a wideband of $10.7 \mathrm{GHz}$ and dual sense 3-dB ARBW of $2.4 \mathrm{GHz}$ and $0.4 \mathrm{GHz}$ for lower and upper bands, respectively. Therefore, the proposed antenna is an attractive choice for broadband and satellite applications.

\section{REFERENCES}

[1] C. A. Balanis, Antenna Theory Analysis and Design, 2nd Edition, Singapore, John Wiley and Sons, 2002.

[2] P. Nageswara Rao and N. V. S .N Sarma, "Koch Fractal Boundary Single feed Circularly Polarized Microstrip Antenna," Journal of Microwaves, Optoelectronics and Electromagnetic Applications, vol. 6, no. 2, pp. 406-413, 2007.

[3] X. Bao and M. J. Ammann, "Dual-frequency dual-sense circularly polarized slot antenna fed by microstrip line," IEEE Transaction on Antennas and Propagation, vol. 56, pp. 645-649, 2008.

[4] C. Chen and E. K. N. Yung, "Dual-band dual-sense circularly-polarized CPW-fed slot antenna with two spiral slots loaded," IEEE Transactions on Antennas and Propagation, vol. 57, pp. 1829-1833, 2009.

[5] V. V. Reddy and N. V. S. N. Sarma, "Triband circularly polarized Koch fractal boundary microstrip antenna," IEEE Antennas and Wireless Propagation Letters, vol. 13, pp. 1057-1060, 2014.

[6] D. Yu, S. X. Gong, Y. T. Wan, and W. F. Chen, "Omnidirectional dual-band dual circularly polarized microstrip antenna using TM01and TM02 modes," IEEE Antennas and Wireless Propagation Letters, vol. 13, pp. 1104-1107, 2014.

[7] C. J. Wang, M. H. Shih, and L. T. Chen, "A Wideband open-slot antenna with dual-band circular polarization," IEEE Antennas Wireless Propag. Lett., vol. 14, pp. 1306 - 1309, 2015.

[8] W. Liang, Y. C. Jiao, Y. Luan and C. Tian, "A dual-band circularly polarized complementary antenna," IEEE Antennas and Propagation Society, vol. 14, pp. 1153-1156, 2015.

[9] D. K. Singh, B. K. Kanaujia, S. Dwari, G. P. Pandey and S. Kumar, "Novel quad-band circularly polarized capacitivefed microstrip antenna for C-band applications," Microwave and Optical Technology Letters, vol. 57, pp. 2622-2628, 2015.

[10] X. L. Bao and M. J. Ammann, "Monofilar spiral slot antenna for dual-frequency dual-sense circular polarization," IEEE Transactions on Antennas and Propagation, vol. 59, pp. 3061 - 3065, 2011

[11] J. G. Baek and K. C. Hwang, "Triple-band unidirectional circularly polarized hexagonal slot antenna with multiple Lshaped slits," IEEE Transaction on Antennas and Propagation, vol. 61, pp. 4831-4835, 2013.

[12] S. Kumar, B. K. Kanaujia, M. K. Khandelwal and A. K. Gautam, "Stacked dual-band circularly polarized microstrip antenna with small frequency ratio," Microwave and Optical Technology Letters, vol. 56, pp. 1933-1937, 2014.

[13] J. Pourahmadazar, C. Ghobadi, J. Nourinia, N. Felegari, and H. Shirzad, "Broadband CPW-fed circularly polarized square slot antenna with inverted L-strip for UWB applications," IEEE Antennas Wireless Propag. Lett., vol. 10, pp. 369-372, 2011

[14] N. Felegari, J. Nourinia, C. Ghobadi and J. Pourhmadazar, "Broadband CPW-fed circularly polarized square slot antenna with three inverted L-shaped grounded strips" IEEE Antennas Wireless Propag. Lett., vol. 10, pp.274 -277, 2011.

[15] K. Ding, T. B. Yu, D. X. Qu and C. Peng, "Broadband CPW-fed circularly polarized falcate-shaped monopole antenna for UWB applications," Frequenz, vol. 68, pp. 305-312, 2014.

[16] S. Patil, A. K. Singh, B. K. Kanaujia and R.L. Yadava, "Design of inclined coupling slot loaded CPW-fed circularly polarized slot antenna for wireless applications," Electromagnetics, vol. 38, no. 4, 226-235, 2018. 
[17] S. Patil, A. K. Singh, B. K. Kanaujia and R.L. Yadava, "Design of dual band dual sense circularly polarized wide slot antenna with C-shaped radiator for wireless applications," Frequenz, vol.72(7-8): 343-351,2017.

[18] S. Patil, A. K. Singh, B. K. Kanaujia and R.L. Yadava, "A low-profile triple-band circularly polarized wide slot antenna for wireless systems," Int. Journal of Microwave \& Wireless Tech., vol. 11, pp. 67-75, 2019.

[19] K. Ding, T. Yu, Q. Zhang and K. Luo, "Dual-band circularly polarized aperture coupled annular-ring microstrip antenna for GNSS applications,” Frequenz, vol. 68, pp. 19-24, 2014.

[20] S. Patil, A. K. Singh, B. K. Kanaujia and R.L. Yadava, "A compact, dual wide-band circularly polarized, modified square ring slot antenna for $\mathrm{C}$ and $\mathrm{Ku}$ band applications," Int. Journal of Microwave \& Wireless Tech., vol. 11, pp. 182-189, 2019. 